\title{
Avaliação da contaminação microbiana da membrana amniótica e líquido amniótico
}

\author{
Evaluation of microbiological contamination of amniotic membrane and amniotic fluid
}

\author{
Carlos Eduardo Borges Souza ${ }^{1}$ \\ Dinorah Piacentini Engel ${ }^{2}$ \\ Bruno Castelo Branco ${ }^{3}$ \\ Ana Luiza Hofling-Lima ${ }^{4}$ \\ Denise de Freitas ${ }^{5}$ \\ José Álvaro Pereira Gomes ${ }^{6}$ \\ Luciene Barbosa de Souza ${ }^{7}$
}

\section{RESUMO}

Objetivos: Verificar a possibilidade de contaminação do líquido amniótico e da membrana amniótica no tempo zero e em diferentes tempos após o parto. Método: Nove amostras de líquido amniótico foram colhidas através de punção uterina. Nove membranas amnióticas foram obtidas de placentas após cesáreas eletivas em gestantes com sorologias negativas (hepatite B, C, sífilis, HIV). Obtiveram-se amostras de membranas amnióticas em três diferentes momentos após o parto (zero, trinta e sessenta minutos). As amostras de membrana foram inoculadas em meios para cultivo bacteriano e fúngico. Resultados: Verificou-se cultivo positivo para bactérias em quatro amostras do líquido amniótico e em todas membranas amnióticas. Staphylococcus coagulase negativo cresceu nas nove membranas estudadas. No tempo zero houve crescimento de Staphylococcus coagulase negativo em todas as membranas, de Staphylococcus aureus em duas, de Enterobacter, Neisseria sp. e Streptococcus viridans em uma cada. No tempo trinta, o Staphylococcus coagulase negativo também cresceu em todas as membranas e o Streptococus viridans em uma. No tempo sessenta, o Staphylococcus coagulase negativo cresceu em oito das nove membranas, o Staphylococcus aureus em duas e o Streptococus viridans em uma. Staphylococcus coagulase negativo foi encontrado em três amostras de líquido e membranas amnióticas correspondentes. Conclusão: Contaminação bacteriana foi evidenciada em todas as membranas amnióticas. Cuidados assépticos devem ser realizados durante todo o manuseio da membrana antes de sua utilização. Estudos quantitativos com maior número de amostras são necessários para comparação mais acurada da variação da contaminação da membrana amniótica em diferentes tempos após a sua retirada.

Descritores: Contaminação; Bactérias; Líquido amniótico; Córnea; Staphylococcus
Departamento de Oftalmologia da Universidade Federal de São Paulo - UNIFESP.

Médico pós-graduando do Departamento de Oftalmologia da Universidade Federal de São Paulo - UNIFESP. ${ }^{2}$ Médica residente do Departamento de Oftalmologia da Universidade Federal de São Paulo - UNIFESP.

${ }^{3}$ Doutor em Oftalmologia pela Universidade Federal de São Paulo - UNIFESP.

${ }^{4}$ Chefe do Departamento de Oftalmologia da Universidade Federal de São Paulo - UNIFESP.

${ }^{5}$ Livre docente do Departamento de Oftalmologia da Universidade Federal de São Paulo - UNIFESP.

${ }^{6}$ Médico voluntário do Departamento de Oftalmologia da Universidade Federal de São Paulo - UNIFESP.

${ }^{7}$ Chefe do Setor de Doenças Externas Oculares e Córnea do Departamento de Oftalmologia da Universidade Federal de São Paulo - UNIFESP

Endereço para correspondência: Rua Alvorada, 81/ 22 - São Paulo (SP) - CEP 04550-000

E-mail: ce.bsouza@uol.com.br

Nota Editorial: Pela análise deste trabalho e por sua anuência na divulgação desta nota, agradecemos ao Dr. Hamilton Moreira

Recebido para publicação em 02.07.2003

Versão revisada recebida em 12.04.2004

Aprovação em 22.04.2004

\section{INTRODUÇÃO}

A membrana amniótica (MA) é a parte mais interna da placenta, composta por uma membrana basal espessa formada de colágeno tipo IV, V e laminina; uma matriz estromal avascular e uma camada epitelial ${ }^{(1-2)}$. É utilizada em oftalmologia pela capacidade de facilitar a adesão e migração das células epiteliais basais, prevenir apoptose e restaurar o fenótipo epitelial ${ }^{(2-3)}$. Além disso, reduz o processo inflamatório, angiogênico e cicatricial e possui documentada ação antimicrobiana ${ }^{(1-2,4-5)}$.

Sua utilização em oftalmologia foi descrita pela primeira vez em 1940, por De Rotth, em cirurgias de reparação de simbléfaro e defeitos conjuntivais, 
com sucesso parcial ${ }^{(6)}$. Em 1946 foi relato bons resultados no uso em queimadura química ocular aguda ${ }^{(7)}$. Seu uso foi quase esquecido até 1995 quando Kim e Tseng começaram a publicar suas experiências clínicas e laboratoriais ${ }^{(2)}$. Recentemente, tem sido utilizada na reconstrução da superfície ocular nos casos de doenças cicatriciais da córnea e conjuntiva, tais como queimadura química, penfigóide cicatricial, eritema multiforme na promoção de cicatrização nos defeitos epiteliais persistentes, como enxerto após remoção cirúrgica de pterígio e tumores, no tratamento de bolhas filtrantes com vazamento, na redução da opacidade corneal após ceratectomia terapêutica, como procedimento inicial antes de transplante de limbo nos casos de deficiência de células germinativas límbicas, e nas reconstruções palpebrais ${ }^{(4,8-14)}$.

A membrana amniótica é separada da placenta obtida de parto cesárea eletivo, sem história de bolsa rota, de pacientes com sorologias negativas para hepatite $\mathrm{B}$ e $\mathrm{C}$, sífilis e HIV. A membrana pode ser usada preservada (MA-P) ou não preservada (MA-NP) ${ }^{(15)}$. A preservação da membrana segue, na maioria das publicações, o protocolo proposto por Tseng et al, no qual a membrana é preparada com antibióticos e antifúngicos e é mantida em meio contendo antibióticos e glicerol, a - $80^{\circ} \mathrm{C}$. Pode ser utilizada até 4 meses após a congelação ${ }^{(3,14)}$. O método de preservação, entretanto, tem um custo elevado e não é disponível em todos os países.

A MA utilizada sem preservação, em condições estéreis, é separada do córion, lavada, irrigada e mantida com solução salina em meio estéril. Após este procedimento, é mantida sob refrigeração sem congelar e utilizada em até $24 \mathrm{~h}^{(15)}$.

Tem sido relatada a contaminação de membranas amnióticas após parto cesárea e contaminação do líquido amniótico tem sido descrita de 13 a $23 \%$ de pacientes com membranas intactas $^{(16-17)}$. Há relatos de casos na literatura de infecção ocular após o uso de membrana não preservada, porém sem confirmação de contaminação da membrana ${ }^{(16)}$. Portanto, existe a necessidade de investigar-se a contaminação do líquido amniótico e das membranas não preservadas, para maior segurança na sua utilização.

\section{MÉTODOS}

As membranas amnióticas foram obtidas de placentas de pacientes do Departamento de Obstetrícia e Ginecologia da UNIFESP e do Hospital Amparo Maternal, submetidas à cesárea eletiva com bolsa íntegra e exames sorológicos negativos. A placenta somente era retirada após consentimento assinado pelas gestantes. A metodologia obedeceu a seguinte rotina:

Antes da abertura uterina, foram colhidos dez mililitros de líquido amniótico (LA) de cada gestante, através de punção com agulha 30x12 mm. O LA era mantido em seringa estéril e inoculado em meio de Brain Heart Infusion (BHI) e tioglicolato.

Nove placentas foram captadas e as membranas processadas da seguinte forma: as amostras da membrana eram retiradas da placenta em dois locais distintos nos tempos zero (momento de retirada da placenta), trinta e sessenta minutos após o parto. Depois de retirada, a placenta era lavada com soro fisiológico a $0,9 \%$ estéril para retirada do excesso de sangue e mantida na mesa cirúrgica em cuba estéril, até a conclusão da retirada das amostras.

Dois fragmentos (um de cada lado do cordão umbilical) eram colocados em $2 \mathrm{ml}$ de BHI e dois eram inoculados em $4 \mathrm{ml}$ de tioglicolato, em diferentes tempos após a retirada dos fragmentos. Todo procedimento foi realizado com material estéril.

Após a colocação em meio de cultivo líquido, as amostras eram incubadas em estufa a $37^{\circ} \mathrm{C}$ por até 7 dias. Quando observado crescimento de microrganismos, as soluções eram replicadas em placas de ágar sangue, chocolate e Sabouraud para cultivo dos microrganismos. Caso não houvesse crescimento as soluções eram desprezadas após sete dias. A identificação das colônias de microrganismos era realizada utilizando os métodos habituais de laboratório.

O protocolo foi submetido e aprovado pelo comitê de ética e pesquisa da UNIFESP.

\section{RESULTADOS}

Das nove amostras colhidas de líquido amniótico (LA), apenas sete estavam apropriadas para estudo microbiológico, pois duas amostras misturaram-se com sangue. Três das amostras do LA apresentaram cultivo positivo com isolamento de Staphylococcus coagulase negativo e outra amostra foi positiva para Candida sp (Tabela1).

Todas as nove amostras de MA colhidas apresentaram crescimento bacteriano em algum dos tempos estudados (Tabela 1). A bactéria mais prevalente foi o Staphylococcus coagulase negativo (100\%), seguido pelo Stapylococcus aureus (33\%), Streptococcus viridans (22\%), Enterobacter sp. e Neisseria sp (10\%) (Tabela 1).

A contaminação microbiana nos diferentes tempos estudados apresentou os seguintes resultados (Gráfico 1):

- No tempo zero, houve crescimento de Staphylococcus coagulase negativo em todas as nove membranas coletadas, de Staphylococcus aureus em duas, Streptococcus viridans, Neisseria sp. e Enterobacter sp., cada um em uma membrana diferente.

- Aos trinta minutos, houve crescimento de Staphylococcus coagulase negativo nas nove membranas e Streptococcus viridans em uma.

- Aos sessenta minutos, houve crescimento de Staphylococcus coagulase negativo em oito das nove membranas, Staphylococcus aureus em duas e Streptococcus viridans emuma.

O tempo trinta minutos diferenciou-se do tempo zero pela ausência de crescimento do Enterobacter sp na membrana 5, da Neisseria sp na 7, e do Staphylococcus aureus nas 2 e 4.

O tempo sessenta minutos diferenciou-se do tempo trinta minutos por apresentar crescimento de Staphylococcus aureus nas membranas 4 e 8 e ausência de crescimento de Staphylococcus coagulase negativo na membrana 2. 


\begin{tabular}{|c|c|c|c|c|}
\hline Pacientes & & Tempo zero & Tempo 30 & Tempo 60 \\
\hline \multirow[t]{2}{*}{1} & MA & CNS & CNS & CNS \\
\hline & LA & CNS & - & - \\
\hline \multirow[t]{2}{*}{2} & MA & CNS; St. Viridans; S. aureus & CNS; St. viridans & St. viridans \\
\hline & LA & Não disponível & - & - \\
\hline \multirow[t]{2}{*}{3} & MA & CNS & CNS & CNS \\
\hline & LA & Negativo & - & - \\
\hline \multirow[t]{2}{*}{4} & MA & CNS; S. aureus & CNS & CNS; S. aureus \\
\hline & LA & Candida sp & - & - \\
\hline \multirow[t]{2}{*}{5} & MA & CNS; Enterobacter sp & CNS & CNS \\
\hline & LA & Negativo & - & - \\
\hline \multirow[t]{2}{*}{6} & MA & CNS & CNS & CNS \\
\hline & LA & Negativo & - & - \\
\hline \multirow[t]{2}{*}{7} & MA & CNS; Neisseria sp & CNS & CNS \\
\hline & LA & Não disponível & - & - \\
\hline \multirow[t]{2}{*}{8} & MA & CNS & CNS & CNS; S. aureus \\
\hline & LA & CNS & - & - \\
\hline \multirow[t]{2}{*}{9} & MA & CNS & CNS & CNS \\
\hline & LA & CNS & - & - \\
\hline
\end{tabular}

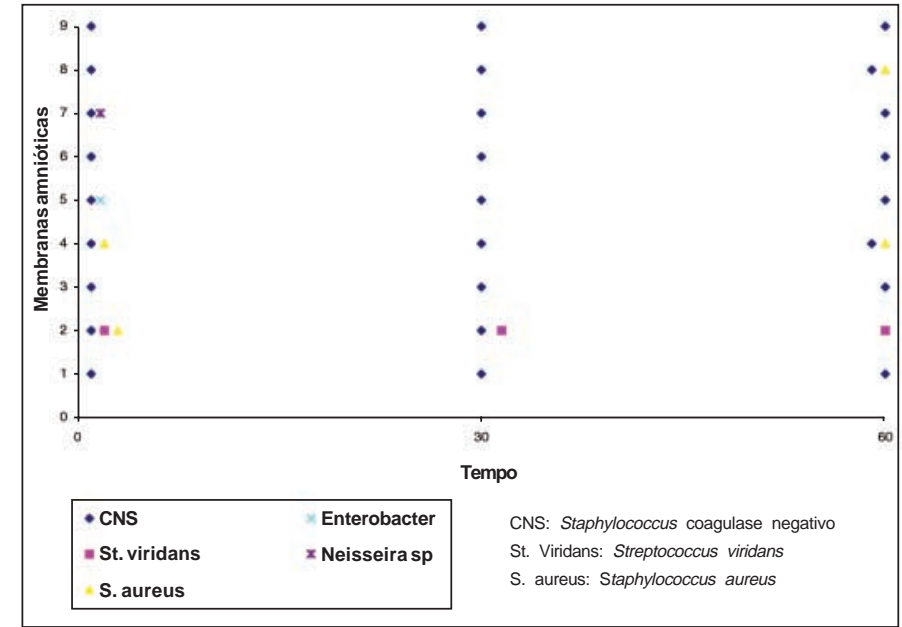

Gráfico 1 - Colonização das membranas amnióticas nos diferentes tempos zero, trinta e sessenta minutos após o parto

O tempo sessenta minutos diferenciou-se do tempo zero por apresentar crescimento de Staphylococcus aureus na membrana 8 e ausência de crescimento de Staphylococcus coagulase negativo $e$ Staphylococcus aureus na membrana 2, assim como ausência de crescimento de Neisseria sp e de Enterobacter $s p$ nas membrana 7 e 5 respectivamente.

\section{DISCUSSÃO}

No presente estudo demonstrou-se que, mesmo envolvendo todos os cuidados assépticos, a freqüência de contaminação da membrana amniótica é elevada. Esta contaminação não variou de forma significativa nos diferentes tempos estudados.
Diversos recursos foram utilizados para aumentar a capacidade de detecção de microrganismos nos líquidos e membranas amnióticas estudadas. Foram retirados fragmentos de lados opostos da membrana em cada tempo. Após o procedimento, diferentes meios de cultivo (BHI e tioglicolato) foram utilizados para possibilitar a detecção de microorganismos aeróbios e anaeróbios.

A contaminação do LA neste estudo foi superior à encontrada por Nisula et al. que relatam uma colonização de $13 \%$ das amostras de pacientes submetidas à cesárea eletiva com bolsa íntegra e sem estar em trabalho de parto e de $23 \%$ em pacientes em trabalho de parto com bolsa íntegra ${ }^{(17)}$. Outros autores observaram contaminação de $23,8 \%$ do LA estudado em pacientes com parto prematuro e bolsa íntegra ${ }^{(18)}$.

A contaminação encontrada nas amostras colhidas de MA estão em concordância com o estudo publicado, no qual houve contaminação bacteriana em todas as 21 amostras de membranas estudadas provenientes de parto normal ou cesárea. Houve maior variedade de patógenos quando a amostra era proveniente de parto normal ${ }^{(19)}$.

Algumas teorias tentam explicar a contaminação da MA e do LA em partos com membranas intactas. Alguns autores acreditam que há infecção ascendente via cérvix ou transplacentária durante a bacteremia materna, o que explicaria tanto a contaminação da MA como do $\mathrm{LA}^{(20)}$, outros sugerem que a contaminação ocorre durante a retirada da placenta, por contato com a ferida cirúrgica ou pela manipulação imprópria ${ }^{(19)}$. As bactérias presentes na MA em seu estudo, pertencem à flora da pele, portanto poderiam ser encontradas na ferida cirúrgica. Os microrganismos mais prevalentes no presente estudo foram da microbiota normal da pele como o Staphylococcus coagulase negativo, o que poderia ser explicado pela 
teoria da contaminação pelo contato com a ferida cirúrgica.

Por outro lado, o presente estudo demonstrou contaminação pelo CNS no LA e MA em 3 das 7 amostras possíveis de comparação, o que pode colaborar com a teoria da contaminação da MA e LA via ascendente.

Um estudo no qual seja coletado material da cervix vaginal e da pele do local a ser realizada a incisão, no parto cesárea, pode elucidar de forma mais acurada a contaminação encontrada na MA e no LA.

Devido à alta prevalência da contaminação das MA-NP, confirmado nesse estudo, sugerimos a irrigação da MA-NP com solução antibiótica, como descrito na literatura para o processo de preservação da $\mathrm{MA}^{(2,14)}$. Portanto, tais cuidados devem ser observados antes da colocação da membrana em recipiente estéril com solução salina, que deve ficar na geladeira por um prazo máximo de 24 horas.

\section{AGRADECIMENTOS}

Ao Hospital Maternidade Amparo Maternal, ao Departamento de Ginecologia e Obstetrícia da Universidade Federal de São Paulo - UNIFESP, ao Laboratório de Doenças Externas Oculares (LOFT) e a Ophtalmos São Paulo.

\section{ABSTRACT}

Purpose: To verify and compare the possible microbiological contamination of amniotic fluid, and amniotic membranes at time zero and at different times after delivery. Methods: Nine amniotic fluid samples were collected by intrauterine aspiration and nine amniotic membranes were collected after cesarean deliveries of patients with negative serology (HIV, syphilis, hepatitis B and C). Samples were collected at different times after delivery (zero, thirty, sixty minutes). The samples were inoculated in culture media for bacteria and fungi. Results: Bacteria were retrieved from four amniotic fluid samples, as well as from all nine amniotic membranes. Coagulase-negative Staphylococcus was the most prevalent bacteria. At time zero, coagulase-negative Staphylococcus was revealed in all nine amniotic membranes, Staphylococcus aureus in two, Neisseria sp., Enterobacter and Streptococcus viridans in one. Thirty minutes after delivery, coagulase negative Staphylococcus grew in all nine amniotic membranes and Streptococcus viridans in one. Sixty minutes after delivery, coagulase-negative Staphylococcus was shown in eight, Staphylococcus aureus in two and Streptococcus viridans in one sample. Coagulase-negative Staphylococcus was found in three amniotic fluids and corresponding membranes. Conclusion: Amniotic membrane contamination was a problem in all samples, and the processing protocol used at the Federal
University of São Paulo was efficient to decontaminate the AM. Care must be taken before the use of AM. Further studies are necessary to establish the accurate variation of AM contamination at different times after delivery.

Keywords: Contamination; Bacteria; Amniotic fluid; Cornea; Staphylococcus

\section{REFERÊNCIAS}

1. Trelford JD, Trelford-Sauder M. The amnion in surgery, past and present. Am J Obstet Gynecol. 1979;134(7):833-45.

2. Kim JC, Tseng SC. Transplantation of preserved human amniotic membrane for surface reconstruction in severely damaged rabbit corneas. Cornea. 1995;14 (5):473-84.

3. Terranova VP, Lyall RM. Chemotaxis of human gingival epithelial cells to laminin. A mechanism for epithelial cell apical migration. J Periodontol. 1986;57(5):311-7.

4. Tsubota K, Satake Y, Ohyama M, Toda I, Takano Y, Ono M, et al. Surgical reconstruction of the ocular surface in advanced ocular cicatricial pemphigoid and Stevens-Johnson syndrome. Am J Ophthalmol. 1996;122(1):38-52.

5. Talmi YP, Sigler L, Inge E, Finkelstein Y, Zohar Y. Antibacterial properties of human amniotic membranes. Placenta. 1991;12(3):285-8.

6. De Roth A. Plastic repair of conjunctival defects with fetal membrane. Arch Ophthalmol. 1940;23:522-5.

7. Sorsby A, Haythorne J, Reed H. Amniotic membrane grafts in caustic soda burns. Br J Ophthalmol. 1947;31:401-4.

8. Tseng SC, Prabhasawat P, Lee SH. Amniotic membrane transplantation for conjunctival surface reconstruction. Am J Ophthalmol. 1997;124(6):765-74.

9. Gomes JAP, Komagome CM, Santos N, Cunha MC, Freitas D. Membrana amniótica nas cirurgias reconstrutivas da superfície ocular nas ceratoconjuntivites cicatriciais. Arq Bras Oftalmol. 1999;62(5):562-76.

10. Lee SH, Tseng SC. Amniotic membrane transplantation for persistent epithelial defects with ulceration. Am J Ophthalmol. 1997;123(3):303-12.

11. Prabhasawat P, Barton K, Burkett G, Tseng SC. Comparison of conjunctival autografts, amniotic membrane grafts, and primary closure for pterygium excision. Ophthalmology. 1997;104(6):974-85.

12. Barton K, Bundenz DL, Khwat PT, Tseng SC. Amniotic membrane transplantation in glaucoma surgery [abstract]. Invest Ophthalmol Vis Sci 1997;38 (Suppl):S473.

13. Choi YS, Kim JY, Wee WR, Lee JH. Effect of the application of human amniotic membrane on rabbit corneal wound healing after excimer laser photorefractive keratectomy. Cornea. 1998;17(4):389-95.

14. Tseng SC, Prabhasawat P, Barton K, Gray T, Meller D. Amniotic membrane transplantation with or without limbal allografts for corneal surface reconstruction in patients with limbal stem cell deficiency. Arch Ophthalmol. 1998;116 (4):431-41.

15. Mejia LF, Acosta C, Santamaria JP. Use of nonpreserved human amniotic membrane for the reconstruction of the ocular surface. Cornea. 2000;19(3):288-91.

16. Khokhar S, Sharma N, Kumar H, Soni A. Infection after use of nonpreserved human amniotic membrane for the reconstruction of the ocular surface. Cornea. 2001;20(7):773-4.

17. Keski-Nisula L, Kirkinen P, Katila ML, Ollikainen M, Saarikoski S. Cesarean delivery. Microbial colonization in amniotic fluid. J Reprod Med. 1997; 42(2):91-8.

18. Ovalle Salas A, Martinez Tagle MA, Gomez MR, Saéz CJ, Menares VI, Aspillago Manterola C, et al. [Premature labor with intact membranes: relationships of amniotic fluid and lower genital tract microbiology with maternal and neonatal outcomes]. Rev Med Chile. 2000;128(9):985-95. id: es.

19. Adds PJ, Hunt C, Hartley S. Bacterial contamination of amniotic membrane. Br J Ophthalmol. 2001;85(2):228-30.

20. Negishi H, Matsuda T, Okuyama K, Sutoh S, Fujioka Y, Fujimoto S. Staphylococcus aureus causing chorioamnionitis and fetal death with intact membranes at term. A case report. J Reprod Med. 1998;43(4):397-400. 